\title{
A Tipografia Nacional Finissecular: Micro-história de um Tipógrafo Orientalista
}

\author{
MARTA PACHECO PINTO \\ Centro de Estudos Comparatistas da Faculdade de Letras \\ Universidade de Lisboa
}

\begin{abstract}
This essay investigates orientalist typography in Portugal from the end of the nineteenth century to the beginning of the twentieth by focusing on the typographer José António Dias Coelho (1858-1940). He served for almost fifty years at the Imprensa Nacional and was responsible for the composition of numerous works published by Portuguese orientalists. I first provide evidence of Dias Coelho's work on Eastern typefaces based on testimonies extracted from books by Portuguese orientalists such as Guilherme de Vasconcelos Abreu, Sebastião Rodolfo Dalgado, and David Lopes. I then present a micro-history of Dias Coelho to evince his role in the genealogy of Oriental Studies in Portugal.
\end{abstract}

Keywords: Typography, Portugal, orientalism, José António Dias Coelho, Imprensa Nacional

A arte tipográfica, pela variedade de elementos que nela se combinam - caracteres, vinhetas, filetes, gravuras, tintas, tonse pelo deslumbramento de efeitos que de todos êsses elementos derivam, não se afasta do ciclo considerado das Belas Artes, cuja posição se reforça pelos requisitos da técnica, habilidade e emoção artística de quem a cultiva, e pelo encanto extasiante que traz aos olhos dos que a admiram. (Canhão 116) 
Quando em 1873 Léon de Rosny criou o Congresso Internacional de Orientalistas, em Paris, era seu propósito reunir uma comunidade de japonólogos, estipulando como dois principais objetivos a cumprir a criação de um plano de traduções de textos fundamentais da tradição literária japonesa e a fixação de um método consensual, ou sistema, de transcrição ortográfica do japonês para línguas ocidentais. ${ }^{1}$ Por um lado, estes objetivos decorriam de uma dificuldade sentida por investigadores europeus que estudavam esta língua asiática, dando assim conta de quem seria o público-alvo daquele tipo de evento científico. Por outro lado, está patente uma preocupação em desenvolver um sistema uniforme de comunicação transnacional de material japonês - não apenas no seio da comunidade orientalista, mas também entre especialistas e os demais agentes envolvidos na produção e disseminação dos seus trabalhos, de que destaco os que os compunham e imprimiam, os tipógrafos, o que, por conseguinte, resultaria numa melhoria da própria qualidade da informação (literária, cultural, científica) veiculada, por via da tradução, da edição crítica ou do ensaio.

A mesma preocupação de uniformização gráfica na transcrição de outros alfabetos orientais para caracteres latinos marcou sessões subsequentes do Congresso Internacional de Orientalistas, como a de Genebra, em 1894, donde saiu um sistema de transcrição de sânscrito e árabe, ou a de Roma, em 1899, em que se discutiram as conclusões do relatório da comissão nomeada no congresso anterior (o de Paris, em 1897) para a elaboração de um sistema único de transcrição de sons chineses. ${ }^{2}$ Determinou-se, porém, que cada país fixasse o seu próprio sistema e o enviasse para coleção num manual internacional.

Em 1892, o filólogo português Aniceto dos Reis Gonçalves Viana (18401914) manifestara-se a favor de uma uniformização de outra natureza, a simplificação da composição tipográfica de caracteres árabes, de forma a facilitar o trabalho dos estudiosos europeus, tanto o de composição como o de leitura de textos que usassem o alfabeto árabe. Lançada numa curta memória inserida no

\footnotetext{
${ }^{1} \mathrm{O}$ presente trabalho de investigação decorre do projeto Textos e Contextos do Orientalismo Português-Congressos Internacionais de Orientalistas (1873-1973), em curso no Centro de Estudos Comparatistas da Faculdade de Letras da Universidade de Lisboa. É financiado pela Fundação para a Ciência e a Tecnologia no âmbito do Projeto 3599-Promover a Produção Científica, o Desenvolvimento Tecnológico e a Inovação-não cofinanciada (PTDC/CPCCMP/0398/2014)

${ }^{2}$ O sanscritista Sebastião Rodolfo Dalgado (Influência do vocabulário português, lxxiii, lxxvii) alude às deliberações do Congresso de Genebra tanto para o devanágari como para o alfabeto arábico, que confirma seguir.
} 
quadro das publicações da décima sessão do Congresso Internacional de Orientalistas, prevista para decorrer, nesse ano de 1892, em Lisboa mas desconvocada de véspera, esta proposta consistia, no fundo, em anular a índole estética - caligráfica - da escrita árabe. Propunha a resolução do que, na sua qualidade de orientalista, Gonçalves Viana descrevia como "defeitos" desse alfabeto, nomeadamente através da supressão dos sinais diacríticos assim como da linha curva que finaliza diversos caracteres, a qual classificava como "embaraçosa" e "inútil" (Simplification 5-6). Encarava esta necessidade de intervenção (ocidental) num sistema ortográfico não-europeu como sendo de "elevada importância para o progresso e a difusão do estudo das línguas que adotaram este sistema de escrita" (Simplification 4). Foi, decerto, uma proposta unilateral de servir e beneficiar tão-só a comunidade orientalista, que não teve consequências de maior, desconhecendo-se, na tipografia nacional, exemplos que a tenham seguido.

Compreende-se, pois, que a qualidade da ciência orientalista então disseminada, entendida como um conjunto de saberes construídos sobre línguas e culturas ditas orientais, e que se pretendia validada e subscrita pela comunidade científica que a consumia, dependia, em grande medida, da qualidade do trabalho de composição e impressão de tipos orientais, presença obrigatória em vocabulários ou gramáticas, e no paratexto de traduções de línguas orientais, em manuais pedagógicos de apoio ao ensino/aprendizagem dessas línguas, em edições críticas de manuscritos e outros textos orientais, em estudos ou até recensões críticas versando o tema.

$\mathrm{Na}$ sua exposição aos membros da Comissão Nacional Portuguesa do Congresso Internacional de Orientalistas de 1873, convocados para formarem uma Associação Promotora do Desenvolvimento dos Estudos Orientais e Glóticos em Portugal, o sanscritista Guilherme de Vasconcelos Abreu (18421907) define "o Orientalismo" em ligação estreita com o progresso das ciências, sobretudo sociais, aproximando-se de uma ideia de interdisciplina assente numa abordagem comparativa; o orientalismo seria então:

[A] somma dos conhecimentos linguisticos, ethnologicos e historicos ácerca dos povos, do Oriente, antigos e modernos. [...] O estudo comparativo dos costumes, das religiões, das mythologias, das philosophias dos povos da antiguidade, tem 
prestado incontestaveis serviços á geografia, á anthropologia, tem confirmado as grandes leis da sociologia e explica phenomenos que a historia não conhecia e outros que ella apenas relatava [...]. (9)

Mais, consciente do movimento europeu em direção ao Oriente e da conjuntura histórica e política de Portugal na segunda metade do século XIX, Vasconcelos Abreu exorta entusiasticamente à criação de meios, em território nacional, que permitam o desenvolvimento da disciplina de Estudos Orientais e, por conseguinte, de uma comunidade interpretativa:

Não podem ser mais auspiciosos os começos. Dentro em pouco podemos ter uma biblioteca, um archivo, um museu digno de uma sociedade de orientalistas, e dentro de alguns annos, se formos homens de energia, poderemos dizer que em Portugal existe essa sociedade, poderemos dizer que nos cabe a gloria de termos acordado o espirito d'este povo adormecido mas apto para os grandes emprehendimentos, poderemos dizer que fizemos a primeira das revoluções - $\mathrm{a}$ da instrucção, poderemos dizer que concorremos para o engrandecimento d'esta nação. (14)

Ora a revolução da instrução, pela leitura e pelo ensino, a par da criação de condições materiais de acesso ao saber (bibliotecas, arquivos, museus), exigiria também um sistema eficaz de produção e de comunicação dos saberes que a sustentam, como o é, por exemplo, a imprensa. Com efeito, no final do século XIX, princípios do de XX, dos paratextos que informam as publicações de orientalistas pela Imprensa Nacional, que em 2018 comemora 250 anos de atividade, destaca-se um nome, o do tipógrafo José António Dias Coelho.

Pretende-se aqui advogar a existência de uma tipografia orientalista no Portugal finissecular, ao dar a conhecer este funcionário do Estado Português que, vivendo à sombra dos livros que compôs e à margem de uma intelligentsia orientalista, concentrada sobretudo em Lisboa e com quem privou fora do círculo estritamente profissional, foi um elemento-chave para assegurar a qualidade dos materiais que imprimiu, chegando a intervir no processo criativo de autores que ficariam na história reputados como orientalistas portugueses. 
Transpõe-se, para o presente estudo, a noção de "micro-histórias" que Jeremy Munday explora a propósito de outros produtores textuais, no caso os tradutores, para mostrar a mais-valia de analisar os percursos biográficos destes agentes, através da recolha de testemunhos de natureza diversa (desde paratextos a outros materiais exogenéticos, como correspondência, manuscritos, contratos), e de os incorporar no estudo dos processos criativos. ${ }^{3}$ Também aqui se fará uma micro-história de um produtor de textos, a de Dias Coelho. Ao contrário do tradutor que pode assinar o seu trabalho - na capa, na ficha técnica ou na folha de rosto de um livro - e tem assim a possibilidade de se tornar visível no paratexto ou aparato crítico, a visibilidade do tipógrafo compositor está dependente da vontade do autor que serve e que, através de agradecimentos ou críticas, pode optar por o nomear no paratexto que ele, autor, assina. Para esta micro-história de um tipógrafo orientalista português, que esteve ativo entre o final das décadas de 1870 e 1920, trar-se-ão à colação materiais encontrados quer no Arquivo Histórico da Imprensa Nacional (INCM/AHIN) quer no Arquivo Nacional da Torre do Tombo (ANTT).

Para cumprir os fins enunciados, dividir-se-á o texto em duas partes: num primeiro momento, argumentar-se-á em favor da exemplaridade do tipógrafo compositor com base na receção do seu trabalho por via dos testemunhos dos seus clientes, sobretudo académicos especialistas em línguas orientais; num segundo momento, far-se-á a micro-história do tipógrafo especialista em caracteres orientais, de forma a atribuir-lhe um lugar na genealogia dos estudos sobre o Oriente em Portugal, o mesmo será dizer do orientalismo português. Deste modo, tornar-se-á saliente um segmento importante e constitutivo da tipografia portuguesa, a tipografia orientalista. Estes objetivos serão cumpridos a par da observação da importância do trabalho de transcrição, composição em caracteres orientais e revisão para garantir a qualidade do saber orientalista posto em circulação em Portugal e, por extensão, a reputação dos próprios orientalistas.

\footnotetext{
${ }^{3}$ Munday baseia-se na proposta do historiador inglês Peter Burke de desenvolver uma "nova história" centrada em grupos ou indivíduos que a história tradicional, mais preocupada com factos, tende a marginalizar: "Burke (1991/2001, 3-6) succinctly contrasts traditional, 'Rankean' history, concerned with 'facts' and first-hand accounts, with the 'new' history of social historians who are interested in the lives of 'ordinary' people or specific groups, such as women, who have tended to be marginalized in traditional history" (66).
} 


\section{Um tipógrafo orientalista}

O orientalismo em Portugal, ao contrário dos orientalismos britânico, alemão, francês ou italiano, não se apoiou na criação de publicações especializadas, antes tirando partido dos boletins ou revistas das sociedades científicas a que os orientalistas estavam ligados e que funcionaram como os principais órgãos de disseminação da sua atividade. São exemplos o Boletim da Segunda Classe da Academia das Ciências de Lisboa, que saiu de 1898 a 1929, o Boletim da Sociedade de Geografia de Lisboa, que se publica desde 1876, ou O Instituto de Coimbra, publicado entre 1852 e 1981. Se o último foi impresso pela Imprensa da Universidade de Coimbra até 1934, data da sua extinção, o primeiro saiu do prelo da Tipografia da Academia das Ciências até 1910, altura em que é dissolvida, sendo a impressão do boletim de 1911 assegurada pela Imprensa Nacional e, a partir de 1912, pela Imprensa da Universidade de Coimbra. O Boletim da Sociedade de Geografia é, a partir de 1882, impresso pela Imprensa Nacional até à primeira década do século XX.

Com efeito, a Imprensa Nacional e a Imprensa da Universidade repartiram entre si a coautoria pela impressão de muitos dos estudos científicos produzidos em Portugal no período finissecular. Se, por exemplo, as revistas orientais então publicadas em Florença beneficiaram "da tipografia de caracteres orientais criada pelos Medici no século XVI" (Vicente 71), as publicações orientalistas impressas em Portugal, tanto periódicas como monográficas, terão beneficiado, por um lado, do saber dos homens que manobravam as prensas e, por outro, da fundição de tipos que a editora oficial do Estado Português tinha à sua disposição. Manuel Canhão não hesita em afirmar que a Imprensa Nacional dispunha, na segunda metade de Oitocentos, "de maiores condições de expansão no fabrico de caracteres" que a colocava "em posição de superioridade perante a produção particular" (56). E é este tipo de condições que, como também relembra, permitiria aos operários oferecer um serviço de qualidade: "Tôda a notabilidade do trabalho do tipógrafo tem a sua base nos caracteres e mais material tipográfico que a fundição de tipos lhe fornece" (Canhão 116).

A pesquisa realizada no âmbito do projeto Textos e Contextos do Orientalismo Português: Congressos Internacionais de Orientalistas (18731973), que resultou na compilação dos trabalhos produzidos pelos participantes portugueses nestes eventos de debate dos Estudos Orientais então praticados, 
veio tornar patente que o orientalismo, enquanto área de estudo(s), teve em Portugal um desenvolvimento mais concentrado e diversificado, em termos de iniciativas autorais e de número de publicações, entre as décadas de 1870 e 1920. Aquando da análise do material paratextual que informa esses trabalhos, detetouse a recorrência de um mesmo nome de tipógrafo compositor em obras impressas, precisamente, durante esse intervalo de tempo, que corresponde aos anos de atividade de Dias Coelho. Os elogios que se tributam a este tipógrafo orientalista fazem adivinhar, como a seguir se verá, uma importante rede de relacionamento interpessoal que vai além da esfera profissional.

Até à data não se conhecem outros trabalhos sobre o orientalismo português que deem conta de agências marginais como a de um tipógrafo compositor, por haver um maior enfoque na atuação de vozes audíveis, tanto por via da sua produção escrita como por meio da sua intervenção sociopolítica. Ora, o que se propõe é mostrar como a agência supostamente marginal de um tipógrafo especialista em caracteres orientais foi determinante para garantir, por um lado, a existência material de um objeto textual e, por outro, a sua qualidade científica. Este intento será cumprido com base não em testemunhos diretos, porque Dias Coelho não os deixou, à exceção dos trabalhos de tipografia que executou, mas por via de testemunhos indiretos, os dos seus clientes, sobretudo académicos. A inclusão de caracteres orientais em trabalhos especializados seria não apenas uma marca formal de exotismo, tanto visual como linguístico, que ajudaria o leitor a localizar o Oriente versado, mas também - ou essencialmente - um indicador da cientificidade do trabalho e um modo de legitimação do saber, ou sabedoria, do autor que os assina, concorrendo para a autoridade do próprio estudo e para o estatuto de especialista do seu autor.

Para além de ter assegurado a composição dos trabalhos de Vasconcelos Abreu, Dias Coelho esteve também envolvido na impressão dos livros do sanscritista Sebastião Rodolfo Dalgado (1855-1922), sucessor de Vasconcelos Abreu no Curso Superior de Letras, ou do arabista David Lopes (1867-1942). O tipógrafo é uma presença constante nos agradecimentos das obras destes autores, que o enaltecem sobretudo como um coadjuvante, cujo ofício desempenhava para além das paredes da oficina tipográfica, indo ao encontro dos seus autores e assistindo-os até na correção das provas. 
Vasconcelos Abreu, no posfácio do seu Manual para o estudo do sãoskrito clássico (1881), destaca o auxílio e profissionalismo do ainda "moço" mas já então "distinto" Dias Coelho:

A disposição typographica, toda a composição, foi dirigida por mim d'accordo com o moço, mas distincto typographo, o sr. Dias Coelho. Sem a coadjuvação constante, proficua, e digna do reconhecimento, que lhe confesso aqui, não sei quando poderia eu fazer imprimir este livro. Durante a doença, que ha anno e meio me estorva de sair como eu careço para desempenho dos meus deveres, muitas horas da noite gastou o sr. Coelho na minha bibliotheca e á cabeceira do meu leito, revendo commigo as provas e combinando a disposição typographica. (173)

Dez anos mais tarde, em Summario das investigações em samscritologia desde 1886 até 1891, Vasconcelos Abreu reitera o elogio ao tipógrafo, descrevendo-o como "mestre de compositores em caracteres orientais, o sr. J. A. Dias Coelho, cujo mérito é digno dos mais subidos elogios" (54). Também Gonçalves Viana já havia confirmado a sua excelência na composição tipográfica em correspondência privada com o linguista alemão Hugo Schuchardt (1842-1927), especialista em crioulos românicos, ao epitetá-lo, numa carta de 6 de outubro de 1888, como "o mais habil compositor da Peninsula" que, entre outros, executou "o tratado em arabe celebrado com o sultão de Zanzibar [a 25 de outubro de 1879], e outros primores da typographia portuguesa."

Na sua introdução à tradução de História dos portugueses no Malabar por Zinadím: manuscrito árabe do século XVI, publicada originalmente pela Imprensa Nacional, em 1898, David Lopes conclui ressalvando que "[n]ão deixaremos de fazer uma referência especial ao nome do Sr. J. A. Dias Coelho, que compôs o texto árabe desta crónica, assim como o texto da nossa Aljamía, publicada em Janeiro: o seu valioso e inteligente auxílio aqui lhe agradecemos" (17). Em Textos em aljamía portuguesa (1897), a respeito dos critérios adotados na transcrição do árabe, David Lopes salienta a variedade de grafias para línguas europeias, inclusivamente dentro do mesmo país, onde "ahi mesmo não ha uniformidade entre os especialistas que se occupam d'esses estudos" (xix). Aludindo à proposta da comissão constituída por ocasião do Congresso dos 
Orientalistas de 1894 para a transcrição de línguas semíticas, de que se considera partidário conquanto a julgue pouco adequada às línguas ibéricas, ressalva que neste trabalho, "como noutras publicações posteriores, tencionamos pô-la de parte desde que escrevamos em português, porque aqui ha normas racionaes que se impõem" (xxii), e expõe, de seguida, o quadro de transcrições que segue, conforme às regras de acentuação portuguesas. Sebastião Rodolfo Dalgado, no seu Glossário luso-asiático (1919), estende a utilidade do acordo de 1894 a outros alfabetos orientais:

O mesmo pode e convêm aproveitar-se para a transcrição dos outros alfabetos que tem idêntica origem, com notação peculiar, fácilmente inteligível, das letras privativas. Importa, portanto, conhecer a transcrição dos alfabetos devanagárico, tamul e árabe-persiano. (L)

IV. O referido Congresso dos Orientalistas tambêm fixou a transcrição do alfabeto arábico, que eu sigo, preferindo as variantes optativas. Mas substituo $d$ por $z$, para evitar a confusão com o $d$ do hindustani, e $w$ por $v$, ou $u$, para manter a harmonia com a transcrição do alfabeto devanagárico.

V. Sendo alguns étimos arábicos reproduzidos das transcrições antigas, devem naturalmente diferir às vezes da transcrição aprovada. (LIV)

O tipógrafo compositor atuaria, portanto, em observância à vontade do autor com quem estaria a colaborar, que poderia diferir da de outro especialista na mesma língua oriental.

Às idiossincrasias de cada autor somar-se-iam outras dificuldades com que Dias Coelho se terá debatido. Trazendo à colação a sugestão de Gonçalves Viana de simplificar a composição tipográfica dos caracteres árabes nas publicações ocidentais, justifica o filólogo a sua proposta com base na pluralidade de formas que cada letra pode assumir, na medida em que "não há uma única que não mude de forma consoante esteja isolada, ligada à letra precedente, à letra seguinte ou a ambas" (3). Exclui da possibilidade de simplificação a escrita devanágari, 
patente, por exemplo, nas obras de Vasconcelos Abreu, por assentar em conexões silábicas, "consistindo cada letra não numa vogal nem numa consoante, mas numa sílaba inteira" (3). Estas terão sido algumas das dificuldades que Dias Coelho enfrentou. Operou com caracteres romanos, asiáticos e outros orientais produzidos nas oficinas da Imprensa Nacional, obedecendo a regras de desenho tipográficas tão diversas quanto a língua oriental em processamento.

José Benoliel (1858-1937), hebraísta e também ele arabista, publicou pela Imprensa Nacional uma tradução hebraica do episódio de Inês de Castro d'Os Lusíadas (1892) e as Fabulas de Loqmán em versos hebraicos (1898), antecedidas da transcrição do texto de partida árabe. Embora não haja qualquer menção paratextual a Dias Coelho, estes trabalhos passaram pelas suas mãos de tipógrafo, compositor e revisor, em parceria com a escola de composição da Imprensa, conforme informação patente no Livro de registo de obras para impressão da Imprensa Nacional (316).

Em Dialecto indo-português de Ceylão (1900), Dalgado faz "testemunhar os meus agradecimentos ao sr. J. A. Dias Coelho, empregado da Imprensa Nacional, pelo seu valioso concurso para a impressão d'esta obra [...] para se publicar por occasião do Centenario [do descobrimento do caminho marítimo para a Índia]" (xi); em Diccionario portuguez-komkanî (1905), Dalgado sublinha a dedicação, "durante todo o decurso, original para a composição e presteza, por vezes excessiva, na revisão de provas, [...] da parte do pessoal da Imprensa Nacional," individualizando em nota o contributo de Dias Coelho: "Devo aqui especialisar com reconhecimento o Sr. José António Dias Coelho pela sua esclarecida e perseverante coadjuvação" (xxi, n. 1). Deixado incompleto, o seu Florilégio de provérbios concanis é publicado postumamente (1922), pela Academia das Ciências mas na Imprensa da Universidade de Coimbra, com revisão-por vontade expressa de Dalgado - de Dias Coelho, que se reformou nesse ano, e do cónego José de Santa Rita e Sousa (1863-1940), professor de Concani na então Escola Colonial de Lisboa:

Tendo ocorrido em 4 de Abril último a morte do orientalista e erudito prof. Mons. S.R. Dalgado, deixando ainda incompleta a publicação dêste livro de Provérbios concanis, incumbiram-se do trabalho da revisão das suas provas, a pedido do falecido, dois amigos seus, o Ex. ${ }^{\text {mo }}$ Sr. José António Dias Coelho, que foi chefe 
de revisão da Imprensa Nacional de Lisboa e a pessoa que subscreve esta nota.

Consistiu pois o nosso trabalho em rever com o maior cuidado possível estas provas desde a fôlha 15 que corresponde a págs. 225 até o fim. Procurámos nesta tarefa respeitar escrupulosamente a letra do original, só alterando por excepção um ou outro vocábulo, onde o lapso do autor parecia evidente, ou introduzindo alguma rara palavra, onde ela parecia necessária para completar o pensamento do autor. (Rita e Sousa 331)

Até à data não se conhecem outras colaborações de Dias Coelho fora da Imprensa Nacional.

O profissionalismo de que estes testemunhos são prova torna-se tanto mais saliente quanto o facto de as publicações compostas, revistas e impressas pelo tipógrafo especialista em caracteres orientais se situarem no campo de produção restrita, consumida, portanto, por um público muito específico de interessados ou savants. ${ }^{4}$ Quer isto dizer que Dias Coelho detinha, assim, o monopólio deste tipo de composição e impressão especializadas na capital portuguesa, para além de, pelo seu trabalho, contribuir para a capitalização da tipografia nacional. Contudo, como ressalva Manuel Canhão, "[s]e para a valorização da tipografia o compositor precisa de reflexão a fim de dispor o texto, de desenho para a ornamentação e de técnica para a execução, tem igualmente de reconhecer-se que se êle não tiver matéria prima nenhum dêsses requisitos vingará" (116).

\section{A micro-história de um tipógrafo orientalista}

Filho de José Joaquim Coelho e Joaquina Maria da Conceição Dias Coelho, José António Dias Coelho nasceu a 19 de março de 1858 em Lisboa, cidade onde veio a falecer a 28 de junho de 1940. Do cruzamento da informação biográfica veiculada no aparato crítico dos textos que fez imprimir com a pesquisa por nós realizada no Arquivo Histórico da Imprensa Nacional, conclui-se que a 26 de fevereiro de 1873, tinha então quinze anos, foi admitido como aprendiz-

\footnotetext{
${ }^{4}$ Não é demais relembrar Bourdieu (123) quando sublinha a interdependência entre o campo de produção restrita ou cultura escolástica, como é o caso das publicações orientalistas, e o sistema educativo, um meio indispensável ao desenvolvimento e crescimento do campo.
} 
compositor na Imprensa Nacional, onde construiu e consolidou a sua carreira profissional. Apresentava à data como habilitações literárias os exames de instrução primária, de português e de francês, para além de deter conhecimentos de inglês e alemão.

Em março de 1877, tornou-se oficial de tipografia. Foi a partir desse ano que se iniciou na execução de trabalhos com caracteres orientais, em que viria a especializar-se com exímio, o que veio a valer-lhe rasgados elogios da parte quer dos autores com quem colaborou, como se viu na secção anterior, quer também da própria Imprensa Nacional. Ciente que estava das exigências da sua atividade, terá sido no final desse ano de 1877 que começou a frequentar aulas de sânscrito, com Vasconcelos Abreu, muito provavelmente no âmbito do curso promovido em anexo ao Curso Superior de Letras, como sugere uma ata manuscrita assinada por Ernesto da Silva, filho do arquiteto real Joaquim Possidónio Narciso da Silva (1806-1896). Este arquiteto, fundador e presidente da Real Associação dos Arquitetos Civis e Arqueólogos Portugueses, foi responsável por reunir em torno de si uma comunidade de interessados em Estudos Orientais, na sequência da sua participação como delegado português no primeiro Congresso Internacional de Orientalistas (o de Paris, em 1873), de que resultou também a iniciativa de constituição da Associação Promotora do Desenvolvimento dos Estudos Orientais em Portugal. Criada por António Augusto Teixeira de Vasconcelos e Guilherme de Vasconcelos Abreu, a Associação consistiria, segundo documento manuscrito de 28 de fevereiro de 1875, numa "sociedade de homens empenhados em fazer que a sua patria se eleve a par das demais nações no cultivo das linguas do antigo e novo Oriente, e no da sciencia da linguagem" (ANTT doc. 2645). ${ }^{5}$ Não tendo, embora, encontrado o nome do tipógrafo compositor entre os sócios da Associação, a sua missão de artífice estava em sintonia com os fins desta sociedade. Na ata da primeira lição de sânscrito dá-se conta de que:

Na primeira lição de Sãoscrito, em 20 de Novembro de 1877 desse o S. ${ }^{r}$ Doutor Vasconcellos e Abreu em presença dos discipulos matriculados a esse curso os $\mathrm{S} .{ }^{\text {rs }}$ Consiglieri Pedrozo, Viannia [sic], Bettencourt Coelho, filho de Jozé Antonio Dias,

\footnotetext{
${ }^{5}$ Este documento é assinado por alguns dos sócios da Associação e faz-se acompanhar dos seus estatutos manuscritos, com data de 29 de maio de 1874 e firmados pelo secretário, e arabista, Augusto Soromenho (1833-1878).
} 
J. da Silva-Ernesto da Silva \& e outros que antes de principiar a lição devia prestar um tributo de gratidão; folgava em vêr o $S{ }^{r}$ Possidónio da Silva presente; e disse que havia dois annos tinha sido procurado em sua caza pelo $\mathrm{S}^{\mathrm{r}}$ Silva delegado do Congresso dos Orientalistas de Paris: convidando-o a fazer parte duma associação que tentava formar para promover os estudos orientaes em Portugal, disse que [...] pedia escusa de não acceitar, mas insistindo o S. ${ }^{\mathrm{r}}$ Silva, elle annuio ao convite; reunio-se com outras pessoas na primeira sessão, entre as quaes figurava o S. ${ }^{\mathrm{r}}$ Marquez d'Avila a quem foi apresentado pelo $\mathrm{S} .{ }^{\mathrm{r}}$ Silva, e disse que o ter ido aperfeiçoar-se ao estrangeiro na lingua sãoscrita, e exercer hoje a cadeira, se o não devia especialmente ao S. ${ }^{\mathrm{r}}$ Silva, pelo menos confessava que muito tinha influido para se fazer conhecido, e portanto pagava publicamente este tributo de gratidão no primeiro dia em que leccionava.

Sete Rios 11 de Janeiro de 187[8]

Ernesto da Silva

(ANTT doc. 2700)

Posto que o manuscrito citado seja um esboço ou uma transcrição da ata original, que terá sido subscrita pelos demais intervenientes, parece haver, além de pequenas imprecisões, um erro de cópia, por antecipação, em "filho de Jozé Antonio Dias, J. da Silva-Ernesto da Silva \& e outros," uma vez que deveria ler-se "Jozé Antonio Dias, Ernesto da Silva—filho de J. da Silva \& e outros." A corroborar a frequência do curso de Sânscrito está a dedicatória que Vasconcelos Abreu atribui a Dias Coelho no primeiro tomo do seu livro Exercicios e primeiras leituras de sámscrito (1889), em que o identifica, ao lado de Gonçalves Viana, de Consiglieri Pedroso e de Barbosa de Bettencourt, como seu discípulo:

A

José Antonio Dias Coelho

Tipógrafo compositor em linguas orientais na Imprensa

Nacional de Lisbôa 
Aniceto dos Reis Gonçalves Vianna

Primeiro oficial da Alfândega de Lisbôa; romanista

\section{Zófimo Consiglieri Pedroso}

Lente da 1. ${ }^{\text {a }}$ cadeira no Curso Superior de Letras em Lisbôa, Deputado às Côrtes e Vereador Municipal

José Francisco Alves Barbosa de Bettencourt

Enjenheiro civil

meu colaborador o primeiro, pe'la arte e dedicação com que tem composto, ele só, os meus trabalhos samscríticos [...];

ofereço êste livro

que lhes recordará o nosso estudo comum no ano lectivo de 1877-1878.

Foi também em 1889 que Dias Coelho participou na Exposição Universal de Paris, através da execução dos trabalhos aí expostos e na qualidade de encarregado da secção de composição das línguas orientais. Desta participação da Imprensa Nacional, que valeu à instituição o Diploma de Honra e medalhas de cooperação a alguns dos seus artistas, porventura ao tipógrafo, dá conta José Vitorino Ribeiro na sua memória A Imprensa Nacional de Lisboa. Apontamentos e subsídios para a sua história: 1768-1912, premiada para o primeiro lugar do concurso aberto a 1 julho de 1912 pela Comissão Promotora dos Festejos do 2. ${ }^{\circ}$ Aniversário da República Portuguesa. Este concurso, que terá vigorado durante 50 dias, destinava-se a estimular a elaboração de uma memória histórica e descritiva sobre a Imprensa Nacional. O júri do concurso foi composto pelo então Inspetor das Bibliotecas Eruditas e Arquivos, Júlio Dantas, pelo Administrador da Imprensa Nacional, Luís Carlos Guedes Derouet, e pelo, entretanto, já Chefe dos Serviços de Revisão da Imprensa Nacional, Dias Coelho.

Retomando ainda o testemunho de Vasconcelos Abreu, os trabalhos que publicou a partir de 1877 na Imprensa Nacional terão sido todos executados por Dias Coelho, através de cuja mestria a empresa estava, assim, "habilitada a 
compor e imprimir qualquer texto oriental, em caracteres devanágricos, ethíopes, árabes, hebraicos, syríacos, persas" (Summario das investigações 54). $\mathrm{Na}$ advertência a uma das suas memórias (1894) para o Congresso dos Orientalistas que acabou por não ter lugar em Lisboa, Francisco Maria Esteves Pereira (18541924), especialista em geês, não é nominativo, fazendo antes um elogio coletivo à indústria portuguesa: "Emfim a Imprensa Nacional é merecedora de muito louvor pela excellente composição material d'esta memoria" (s.p.).

Em Exposição da pronuncia normal portuguesa, de 1892, Gonçalves Viana reitera "a diligencia e intelligente direcção e execução empregadas na Imprensa Nacional de Lisbôa em todos os trabalhos que lhe são confiados" (27). Não deixa de ser curioso constatar, no mesmo opúsculo, que Gonçalves Viana se escuda no prazo estipulado para a impressão da memória para justificar a ausência de exemplos que deveriam ter sido incorporados de suporte à sua argumentação, tendo, portanto, o cuidado de eximir o tipógrafo compositor ou a editora de qualquer responsabilidade sobre o produto final: "Na transcrição monogrammática das consoantes que temos organizada, mas que por difficuldades typográphicas invencíveis nesta urgencia de tempo não pode ser, como dissemos, dada á estampa por agora" (28). Mais, explica os modos de transcrição usados pela Imprensa Nacional, que combinava a transcrição monogramática, "quando as principaes divisões dos sons são expressas por caracteres distintos" (26), com a transcrição diacrítica, quando "só as principaes distinções dos sons se representam por caracteres distintos, sendo as outras differenciações marcadas com diversos signaes acrescentados ás letras" (27). Estes modos de transcrição não seriam, porém, adotados de forma apriorística, mas antes acordados entre autor e tipógrafo compositor. De novo se infere que Dias Coelho seria competente não apenas na transcrição dos manuscritos e na aplicação de tipos orientais, mas também a negociar o modo de transcrição e transliteração, ou romanização, mais adequado aos demais alfabetos orientais.

Dias Coelho foi, no ano de 1892, um dos responsáveis pela impressão dos trabalhos preparados para o supracitado $\mathrm{X}$ Congresso Internacional de Orientalistas; terá feito imprimir, em parceria com os alunos da escola de composição da Imprensa Nacional, para além dos trabalhos já mencionados, e entre outros, os dois volumes da Chronica de Susenyos, rei de Ethiopia (em 1892 e 1900, respetivamente), de Esteves Pereira, O Oriente e a América, do explorador e etnógrafo António Lopes Mendes (1835-1894), ou Os ciganos em 
Portugal, do pedagogo e etnolinguista Francisco Adolfo Coelho (1847-1919) (INCM/AHIN, Livro de registo 284, 304).

Na secção noticiosa do periódico macaense $A$ Voz do Crente de 22 de outubro de 1892, reproduz-se uma notícia publicada originalmente num jornal lisboeta relativa aos trabalhos inscritos para o Congresso de Lisboa, em que se reserva um parágrafo de elogio ao trabalho artístico da Imprensa Nacional:

Os outros trabalhos importantes estão concluidos, que serão, além de tudo, um novo e honroso titulo para a nossa imprensa, onde sob a direcção de modestos e acrisolados artistas, como os snrs. Coelho, Cosmelli e outros, se fazem trabalhos e reproduções documentaes, em arabe, hebraico, abyssinio, sanscripto, concani, etc., como raramente se fazem lá fóra. (351)

A par do nome de Dias Coelho indica-se o de Júlio César Cosmelli, que foi gravador e fotógrafo da Imprensa Nacional, responsável pelas reproduções fototípicas que Vasconcelos Abreu incluiu no seu Summario das investigações em samscritologia.

Não se sabe com que rendimento Dias Coelho entrou para a Imprensa Nacional nem em quanto terá sido bonificado em 1891 ao ascender a chefe de secção tipográfica. No entanto, de acordo com a sua ficha de serviço, em janeiro de 1897 recebia o vencimento de 1.500 réis diários, a 22 de outubro de 1900, com a nomeação para o lugar de chefe de revisão por ocasião da morte de José Augusto da Silva, passou a auferir mais 400 réis, ou seja, 1.900 réis diários, e a 1 de junho de 1902 estava a ganhar 2.100 réis, um aumento gradual que dá bem conta da sua produtividade e rentabilidade dentro da instituição. Segundo o testemunho de Norberto de Araújo e Artur José Pereira Mendes, num manuscrito preparado para o referido concurso dos festejos da 2. ${ }^{a}$ República, que não chegou a ser publicado por não ter obtido prémio, “[c]aprichou o citado empregado em dar à secção que lhe haviam dado para dirigir uma orientação especial, que, como dissemos, antes não tinha, regulando a leitura, e fasendo passar antecipadamente pela sua meza todos os documentos originaes e provas vindas de todas as secções" (f. 18).

Essa orientação especial passou também pela uniformização da ortografia portuguesa. A este chefe dos serviços de revisão se deve a reforma ortográfica de 
1911, por ter sido o seu principal instigador. A 17 de dezembro de 1910, Dias Coelho oficiou Luís Derouet, alertando para a anarquia que proliferava em matéria de ortografia pelas publicações da Imprensa Nacional e advertindo para a urgência de se fixar regras ortográficas:

As publicações saídas da Imprensa Nacional, quer oficiais, quer de particulares, apresentam grafias diferentes, umas discutiveis, outras porêm grosseiras e vergonhosas. O próprio Diário do Govêrno, que deveria ter ortografia uniforme, emprega diversas, conforme o capricho de quem envia os originais, geralmente pessoas indoutas.

Tais variedades de grafias trazem para a Imprensa não só descrédito mas tambêm prejuizos pecuniários, porquanto a composição de todos os diplomas saídos no Diário tem de transitar para outras publicações periódicas, [...] sofrendo então cada um dêsses diplomas mais emendas, ao sabor de quem tem de lhes fazer nova revisão.

Tantas emendas, alêm de estabelecerem confusão no espírito do compositor, avolumam de uma maneira assombrosa a despesa da composição, e impedem a rapidez na impressão pelo muito tempo que se perde a fazer alterações.

Com esta anarquia ortográfica os compositores hesitam e cometem novos erros, e aos revisores se torna tambêm impossível fixar, para cada obra, as divergências de tanta grafia.

Urge, portanto, acabar com êste estado de cousas. Fácil me parece o remédio. Se cada qual se tem julgado até aqui com direito a impor a sua maneira de escrever, porque razão o Govêrno da República não ha de impor tambêm a sua, e no que é seu? (Direção Geral 3)

Recomendava então que se adotasse como manual a Ortografia nacional: simplificação e uniformização sistemática das ortografias portuguezas (1904), de Gonçalves Viana. A 14 de janeiro de 1911, Luís Derouet, subscrevendo o apelo de Dias Coelho, oficiou o Diretor Geral de Instrução Secundária, Superior e Especial, "fazendo varias considerações tendentes a manifestar o seu acordo 
com a materia defendida no oficio do chefe da revisão da Imprensa Nacional, cujo oficio juntamente enviava" (Araújo e Mendes, f. 250). Um mês depois, a 15 de fevereiro, o Ministro do Interior António José d'Almeida nomeava uma comissão para fixar as bases ortográficas da língua portuguesa, constituída por Adolfo Coelho, que a veio a presidir, Carolina Michaëlis de Vasconcelos, Gonçalves Viana, Cândido de Figueiredo e Leite de Vasconcelos. A 16 de março de 1911, foram agregados novos vogais de apoio à comissão e, ainda nesse ano, foram publicadas as Bases para a unificação da ortografia que deve ser adoptada nas escolas e publicações oficiais. Norberto de Araújo e Artur Mendes são perentórios a afirmar que "[a] iniciativa desta reforma deve-se, pois, a Dias Coelho, chefe dos serviços da revisão da Imprensa Nacional" (f. 251); também o relatório da comissão lhe faz jus ao reproduzir, nas primeiras páginas, o ofício que saiu do seu Gabinete e os que se lhe seguiram.

Entre 1914 e 1916, Dias Coelho foi vogal efetivo do Conselho Disciplinar da Imprensa Nacional. Em 1922, foi louvado pelo modo como dirigiu os trabalhos impressos da Conferência Parlamentar Internacional de Comércio, que reunira em maio de 1921 no Palácio do Congresso em Lisboa. Em 1923, uma ordem de serviço expedida na sua instituição dava também conta de um louvor público do Governo Português à Imprensa Nacional e aos seus artistas, incluindo Dias Coelho, por conta do trabalho de impressão da obra Ordens militares portuguesas e outras condecorações, mandada publicar pelo Ministério da Guerra; de acordo com a portaria que saiu na segunda série do Diário do Governo (n. $\left.{ }^{\circ} 266\right)$ :

Manda o Govêrno da República Portuguesa, pelo Ministro da Guerra, que à direcção daquele estabelecimento do Estado, na pessoa do seu director, Luís Derouet, seja dado um público louvor e bem assim aos artistas portugueses, todos funcionários do mesmo estabelecimento, Ricardo Maria da Costa, Júlio Pereira, José António Dias Coelho, Alfredo Romão do Nascimento, Eduardo Alves Correia, Alberto Silva, Eduardo Lopes Júnior e mais pessoal que auxiliou a obra mencionada, pelo muito zêlo, desvelado interêsse e finalidade artística que impuseram a essa obra, que bem se pode enfileirar entre as 
primeiras do estrangeiro, honrando assim o estabelecimento do Estado a que pertencem.

Paços do Govêrno da República, 10 de Novembro de 1923.-O Ministro da Guerra, António Maria da Silva. (INCM/AHIN, Livro de ordens de serviço $\mathrm{n}^{\circ}{ }^{3} 31$ )

Desde 4 de junho de 1922 que Dias Coelho passara, contudo, à reforma. Foi um funcionário exemplar da Imprensa Nacional, estando essa exemplaridade registada em respetiva ordem de serviço por ocasião da sua reforma:

[E]sta Direcção Geral exprime a mágoa de ver afastar do serviço quem, em perto de 50 anos de labor quási constante, deu á Imprensa, em várias conjunturas, as provas mais irrecusáveis do seu zêlo e da sua inteligência, contribuindo não poucas vezes, com os seus vastos conhecimentos, para que o Estabelecimento gozasse uma reputação acima da vulgaridade. (INCM/AHIN, Livro de ordens de serviço n. ${ }^{\circ} 296$, de 31 de maio de 1922; Livro de matricula $\mathrm{f} .100)$

Do mesmo Livro da matricula do pessoal, registam-se tão-só 12 dias de faltas a Dias Coelho por motivo de doença, de 9 a 20 de junho de 1914, o que abona em favor da sua dedicação não apenas à casa, mas também às letras e à ciência portuguesas.

\section{Notas coadjuvantes}

Dias Coelho não foi um intelectual, não deixando, por isso, qualquer tipo de legado escrito. Foi um leitor privilegiado, porventura um dos primeiros leitores, dos manuscritos que lhe chegavam às mãos para decifrar, compor, rever e imprimir, tendo assim sido responsável pela materialização de inúmeras ideias (manuscritas) em objetos textuais (livros) destinados a serem consumidos por uma elite da cultura portuguesa.

Este operário da classe tipográfica, considerado de "raros conhecimentos e profundamente estudioso" (Araújo e Mendes f. 248), foi não apenas um executante de composição tipográfica e artista de tipos orientais, mas sobretudo 
um coadjuvante do orientalismo e da comunidade orientalista nacionais, que beneficiaram do seu saber, empenho e técnica para produzir ciência no final do século XIX e primeiras décadas do século XX. Dos vários testemunhos aqui cotejados, fica patente o seu contributo decisivo para a construção e acumulação de capital científico e académico sobre diversos Orientes em Portugal.

Estando, embora, por fazer a história do prelo de tipos orientais na Imprensa Nacional, tal como Dias Coelho outros tipógrafos versados em caracteres orientais houve, estabelecidos quer em Lisboa quer em Coimbra ou no Porto, onde continua a estar concentrada a indústria tipográfica portuguesa, e cujas micro-histórias é importante escrever e colacionar para compreender a evolução da tipografia orientalista, que foi também uma tipografia científica e é espelho das diferentes fases de desenvolvimento dos Estudos Orientais em Portugal.

\section{Obras Citadas}

Actes du douzième Congrès international des orientalistes, Rome 1899: tome premier, résumé des bulletins-Inde et Iran. Société Typographique Florentine, 1901.

Araújo, Norberto de, e Artur José Pereira Mendes. Ms. Imprensa Nacional de Lisboa, memoria historica — notas de arte, antecedentes, descrições, critica, documentos. Biblioteca da Imprensa Nacional, 1912.

Arquivo Nacional da Torre do Tombo. Arquivo Possidónio da Silva, Correspondência artistica e scientifica nacional e estrangeira com J. Possidónio da Silva, 1874-1880, vol. 4 (4. $\left.{ }^{\circ}\right)$, cx. 5.

Bourdieu, Pierre. The Field of Cultural Production, tradução de Randal Johnson, Polity, 1993.

Canhão, Manuel. Os caracteres de imprensa e a sua evolução histórica, artística e económica em Portugal. Grémio Nacional dos Industriais de Tipografia e Fotogravura, 1941.

Congrès international des orientalistes: compte-rendu de la première session. Paris, 1873, vol. 3, Maisonneuve, 1878.

Dalgado, Sebastião Rodolfo. Florilégio de provérbios concanis. Imprensa da Universidade, 1922.

—. Glossário luso-asiático, vol. 1, Imprensa da Universidade, 1919. 
-. Influência do vocabulário português em línguas asiáticas: abrangendo cerca de cinquenta idiomas. Imprensa da Universidade, 1913.

—. Diccionario portuguez-komkanî. Imprensa Nacional, 1905.

—. Dialecto indo-português de Ceylão. Imprensa Nacional, 1900.

Direção Geral de Instrução Secundária, Superior e Especial do Ministério do Interior. Bases para a unificação da ortografia que deve ser adoptada nas escolas e publicações oficiais: relatório da comissão nomeada por portaria de 15 de fevereiro de 1911 novamente revisto pelo relator. Imprensa Nacional, 1911.

Dixième Congrès international des orientalistes, Session de Genève: Rapport de la commission de transcription. E. J. Brill, 1894.

Gonçalves Viana, Aniceto dos Reis. "Carta a Hugo Schuchardt (Brief 0403878)." Hugo Schuchardt Archiv, Universität Graz. schuchardt.unigraz.at/id/letter/1551.

- Exposição da pronuncia normal portuguesa para uso de nacionaes e estrangeiros: memoria destinada a X sessão do Congresso Internacional dos Orientalistas. Imprensa Nacional, 1892.

- Simplification possible de la composition en caractères arabes: mémoire présenté à la 10ème. session du Congrès international des orientalistes. Imprimerie Nationale, 1892.

Imprensa Nacional-Casa da Moeda. Livro de matricula do pessoal existente em 1 de Julho de 1901 e do admittido d'esta data em deante, livro 1 (1-251). Arquivo Histórico da Imprensa Nacional, 1839-1887.

- Livro de ordens de serviço, $n{ }^{\circ} 181$ a 360, de Maio de 1917 a Dezembro de 1924. Arquivo Histórico da Imprensa Nacional, 1917-1924.

—. Livro de registo de obras para impressão, n. ${ }^{\circ}$ 720. Arquivo Histórico da Imprensa Nacional, Lisboa, 1892.

Lopes, David. "Zinadím e a sua obra." História dos portugueses no malabar por Zinadím, tradução de David Lopes, 1898, Antígona, 1998, pp. 11-17.

—. Textos em aljamía portuguesa. Imprensa Nacional, 1897.

Munday, Jeremy. "Using Primary Sources to Produce a Microhistory of Translation and Translators: Theoretical and Methodological Concerns." The Translator, vol. 20, no. 1, 2014, pp. 64-80. 
Pereira, Francisco Maria Esteves. Vida do Abba Samuel do Mosteiro do Kalamon, versão ethiopica. Imprensa Nacional/Sociedade de Geografia de Lisboa, 1894.

Ribeiro, José Vitorino. A Imprensa Nacional de Lisboa: apontamentos e subsídios para a sua história: 1768-1912. Imprensa Nacional, 1912.

Rita e Sousa, José de. "Nota da revisão." Glossário luso-asiático, de Sebastião Rodolfo Dalgado, Imprensa da Universidade, 1922, pp. 331-32.

Vasconcelos Abreu, Guilherme. Exposição feita perante os membros da Commissão Nacional Portugueza do Congresso Internacional dos Orientalistas convocados para constituirem uma Associação Promotora dos Estudos Orientaes e Glotticos em Portugal. Wood, 1874.

- Manual para o estudo do sãoskrito classico: curso de litteratura e lingua sãoskritica classica e vedica. Imprensa Nacional, 1881.

-. Summario das investigações em samscritologia desde 1886 até 1891: opúsculo escripto a convite da commissão organizadora do Congresso Internacional de Orientalistas, Londres, 1891. Imprensa Nacional, 1891.

-. Exercicios e primeiras leituras de sámscrito (apéndice ao manual), tômo I: gramática e antolojía. Imprensa Nacional, 1889.

Vicente, Filipa Lowndes. Outros orientalismos: a Índia entre Florença e Bombaim, 1860-1900. Imprensa de Ciências Sociais, 2009.

A Voz do Crente, vol. 6, no. 305, 22 out. 1892. 